\title{
Radical Polymerization of 5-(4-Vinylphenyl)-10,15,20-triphenyl Porphyrin
}

\author{
Atsushi Kajiwara, Kaoru Aramata, Mikiharu Kamachi, ${ }^{\dagger}$ \\ and Katsuhiro SUMI* \\ Department of Macromolecular Science, Faculty of Science, Osaka University, \\ Toyonaka, Osaka 560, Japan \\ * Institute of Applied Biochemistry, University of Tsukuba, \\ Tsukuba, Ibaraki 305, Japan.
}

(Received August 30, 1993)

\begin{abstract}
Radical polymerizations of vinyl monomer in which vinyl group directly bind to a tetraphenyl porphyrin (TPP) moiety, 5-(4-vinylphenyl)-10,15,20-triphenylporphyrin (VTPP), were investigated. Homopolymerization occurred and high-molecular weight polymers $\left(\bar{M}_{w}\right.$ $>100000)$ were obtained. Copolymerizations of VTPP $\left(M_{1}\right)$ and styrene $\left(M_{2}\right)$ were performed with $2,2^{\prime}$-azobis(isobutyronitrile) (AIBN) at $60^{\circ} \mathrm{C}$. Monomer reactivity ratios were $r_{1}=0.65 \pm 0.15$ and $r_{2}=0.51 \pm 0.15, Q$ and $e$ for VTPP being 0.85 and 0.24 , respectively. These values suggest a slightly distorted structure of propagating radicals. Rate constant of the addition of diphenyl phosphinoyl radicals $\left(\mathrm{Ph}_{2} \dot{\mathrm{P}}=\mathrm{O}\right)$, generated by the photolysis of 2,4,6-trimethylbenzoyl diphenylphosphine oxide (TMDPO), to VTPP was directly determined by time-resolved electron spin resonance (ESR) spectroscopy. The rate constant, $\sim 1.4 \times 10^{6} \mathrm{~s}^{-1} \mathrm{M}^{-1}$, was one order of magnitude smaller than that of styrene $\left(\sim 1.1 \times 10^{7} \mathrm{~s}^{-1} \mathrm{M}^{-1}\right)$, due to decrease of resonance stabilization caused from a steric hindrance of TPP moiety.
\end{abstract}

KEY WORDS Tetraphenylporphyrin / Radical Polymerization / Copolymerization / $Q, e$ Values / Monomer Reactivity Ratio / Time-Resolved ESR / Initiation Rate Constant /

Polymers containing paramagnetic species in their side chains are potentially new magnetic materials, because a magnetic ordering of the paramagnetic species through an exchange interaction of unpaired electrons is possible in the polymers. ${ }^{1-3}$ To our knowledge, the radical homopolymerization of vinyl monomers containing a porphyrin moiety in the side chain has not been reported except in our previous papers. ${ }^{4-6}$ The homopolymerizations of such monomers have been considered difficult due to steric repulsion. We synthesized poly-acrylate, -methacrylate, -acrylamide, and -methacrylamide of tetraphenylporphyrin(poly(5-[4-(acryloyloxy)phenyl]10,15,20-triphenylporphyrin), AOTPP, ${ }^{4,5}$ poly(5-[4-(methacryloyloxy)phenyl-10,15,20triphenylporphyrin), MAOTPP, ${ }^{5}$ poly(5-[4acrylamidophenyl]-10,15,20-triphenylporphy-

\footnotetext{
$\dagger$ To whom correspondence should be addressed.
}

rin), AATPP, ${ }^{6}$ and poly(5-[4-methacrylamidophenyl]-10,15,20-triphenylporphyrin), MAATPP, ${ }^{7}$ respectively) and investigated physicochemical properties of their metal complexes. $^{8-11}$ We measured the magnetic susceptibility of polymers containing paramagnetic metalloporphyrin moieties in their side chains. Although the silver(II) complex of polyAOTPP showed strong antiferromagnetic interaction, the silver(II) complex of monomer (AOTPP) showed a typical paramagnetic property. ${ }^{2}$ Polymer effect on the magnetic ordering was found in the system, but the origin of the exchange interactions among these paramagnetic side chains still remains unknown. The strong antiferromagnetic interaction of polyAOTPP-AgII is likely due to a superexchange interactions through oxygen atoms of carbonyl group suggested from an IR 
spectrum of silver(II) complex. ${ }^{2}$ Accordingly we attempted to synthesize a similar polymer with paramagnetic side chains without oxygen atoms in its structure.

Recently, we succeeded in preparing a homopolymer of vinyl monomer in which vinyl group directly binds to a tetraphenyl porphyrin (TPP) moiety, the 5-(4-vinylphenyl)10,15,20-triphenylporphyrin (VTPP). Although VTPP has a larger steric hindrance around the vinyl groups than those of above TPP-containing monomers, polymerization occurred and high molecular weight homopolymers $\left(\bar{M}_{w}>100000\right)$ were obtained. We investigated radical polymerizabilities of VTPP through copolymerization with styrene and time-resolved ESR spectroscopy. In this paper, we report the homopolymerization of VTPP, and the copolymerization of VTPP with styrene.

\section{EXPERIMENTAL}

\section{Materials}

Diethyl ether, tetrahydrofuran (THF), benzene, and benzonitrile were purified by distillation according to usual methods. ${ }^{12}$ Methyl iodide, propionic acid, sulfuric acid, and acetic acid were used as commercial grade. Terephthalaldehyde was ground and dried over $\mathrm{P}_{2} \mathrm{O}_{5}$ in vacuo. 2,2'-Azobis(isobutyronitrile) (AIBN) was recrystallized from diethyl ether. Styrene was purified according to an usual manner and distilled under reduced pressure over $\mathrm{BaO}$ just before use.

Synthesis of monomer (VTPP) was summarized in Scheme 1.

\section{4-(1-Hydroxyethyl)-benzaldehyde (1)}

Terephthalaldehyde $(50.0 \mathrm{~g}, 0.373 \mathrm{~mol})$ was dispersed into anhydrous diethyl ether. Diethyl ether solution of methylmagnesium iodide which was prepared from methyl iodide $(25.9 \mathrm{ml}, 0.419 \mathrm{~mol})$ and magnesium $(10.2 \mathrm{~g}$, $0.418 \mathrm{~mol}$ ) was dropped into the above suspension mixture with stirring. The reaction mixture was poured into $1 N$ aq $\mathrm{HCl}(400$ $\mathrm{ml}$ ) for hydrolysis. The reaction mixture was extracted with diethyl ether three times and the combined organic layer was washed with aqueous $\mathrm{NaHCO}_{3}$ and water. After evaporation of diethyl ether, the residual oil was steam

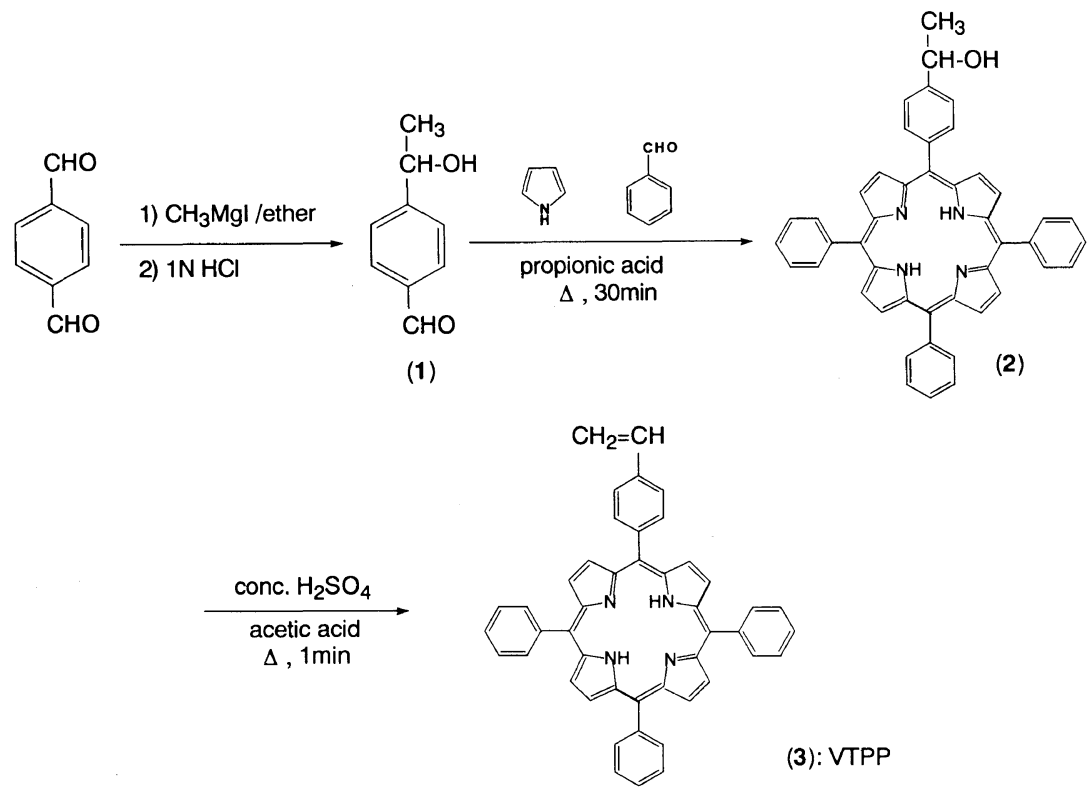

Scheme 1. 
distilled to remove unreacted terephthalaldehyde. Its residue was extracted with diethyl ether, and the solvent was removed under reduced pressure. $\mathrm{NaHSO}_{3}(40 \mathrm{~g})$ was added to the residual oil with stirring. Water and diethyl ether were added and the ether layer was separated to remove components which did not dissolve in water. The water layer was neutralized with $2 \mathrm{~N}$ aq $\mathrm{NaOH}$. The aqueous solution was extracted with diethyl ether and the organic layer was dried over anhydrous $\mathrm{Na}_{2} \mathrm{SO}_{4}$. The organic layer was concentrated to give yellow oil in $21.9 \%$ yield $(12.27 \mathrm{~g})$. IR (KBr) $3400 \mathrm{~cm}^{-1}, v_{\mathrm{O}-\mathrm{H}}\left(\right.$ lit. $\left.{ }^{13} 3420 \mathrm{~cm}^{-1}\right), 1700$ $\mathrm{cm}^{-1}, \quad v_{\mathrm{C}=\mathrm{o}}\left(\right.$ lit. $\left.^{13} 1694 \mathrm{~cm}^{-1}\right) ;{ }^{1} \mathrm{H}$ NMR $\left(\mathrm{CDCl}_{3}, 100 \mathrm{MHz}\right), \delta 1.55(\mathrm{~d}, 3 \mathrm{H}, J=6 \mathrm{~Hz})$, $\delta 2.62(\mathrm{~s}, 1 \mathrm{H}), \delta 4.98(\mathrm{q}, \quad 1 \mathrm{H}, \quad J=6 \mathrm{~Hz})$, $\delta 7.44-7.94(\mathrm{~m}, 4 \mathrm{H}), \delta 9.94(\mathrm{~s}, 1 \mathrm{H})$. Anal. Calcd for $\mathrm{C}_{9} \mathrm{H}_{10} \mathrm{O}_{2}$ : C, $71.98 \% ; \mathrm{H}, 6.71 \%$, Found: C, $71.62 \%$; H, 6.68\%.

5-[4-(1-Hydroxyethyl)phenyl]-10,15,20-triphenyl porphyrin (2)

$1(5.4 \mathrm{~g}, 35.6 \mathrm{mmol})$ and benzaldehyde $(11.3 \mathrm{~g}, 106.8 \mathrm{mmol})$ were dissolved in $200 \mathrm{ml}$ of propionic acid and heated to reflux. Pyrrole $(9.6 \mathrm{ml}, 142.4 \mathrm{mmol})$ was added dropwise to the reaction mixture. After refluxing for $30 \mathrm{~min}$ with stirring, the reaction mixture was cooled to room temperature and the solvent was evaporated. Methanol was poured into the residue and the solution was refluxed for $1 \mathrm{~h}$. After cooling, the supernatant was removed and the residual dark brown solid was dissolved in dichloromethane. This solution was washed with water and aq $\mathrm{NaHCO}_{3}$. The organic layer was dried over anhydrous $\mathrm{Na}_{2} \mathrm{SO}_{4}$. Dichloromethane was removed by evaporation, and the crude product was chromatographed on a silica gel column (Wakogel C-200, $5.6 \times 24.4 \mathrm{~cm}$ ) with dichloromethane twice. Second fractions were collected and the solvent was removed by evaporation. The residual purple solid was recrystallized from dichloromethane-methanol and dried in vacuo. 2 was obtained as reddish purple micro crystal in $3.47 \%$ yield $(1.21 \mathrm{~g}) . \mathrm{mp}>300{ }^{\circ} \mathrm{C} ;{ }^{1} \mathrm{H}$ NMR $\left(\mathrm{CDCl}_{3}, 400 \mathrm{MHz}\right) \delta-2.69(\mathrm{~s}, 2 \mathrm{H}), \delta 1.52(\mathrm{~s}$, $1 \mathrm{H}), \delta 1.82(\mathrm{~d}, 3 \mathrm{H}, J=6 \mathrm{~Hz}), \delta 5.26(\mathrm{q}, 1 \mathrm{H}$, $J=6 \mathrm{~Hz}), \delta 7.27-7.82(\mathrm{~m}, 11 \mathrm{H}), \delta 8.14-8.26$ $(\mathrm{m}, 8 \mathrm{H}), \delta 8.88(\mathrm{~s}, 8 \mathrm{H})$. FD-Mass Calcd. 658, Found 657.9.

\section{5-(4-Vinylphenyl)-10,15,20-triphenyl porphyrin} (VTPP) (3)

$2(0.70 \mathrm{~g}, 1.03 \mathrm{mmol})$ was dissolved in acetic acid $(75 \mathrm{ml})$. The solution was heated to reflux. $3.5 \mathrm{ml}$ of concentrated sulfuric acid were added to the solution and stirred for $1 \mathrm{~min}$. The reaction mixture was poured into $c a .150 \mathrm{~g}$ of ice and was neutralized with aq $\mathrm{NaOH}$. After extraction with dichloromethane, the organic layer was washed with aq $\mathrm{Na}_{2} \mathrm{CO}_{3}$. The solvent was removed and the residue was chromatographed on a silica gel column (Wakogel C-200, $2.5 \times 23.0 \mathrm{~cm}$ ) with dichloromethane. The first fraction was collected. The solvent was removed by evaporation, and the residual crude product was recrystallized from dichloromethane-methanol and dried in vacuo with heating at $60^{\circ} \mathrm{C}$. VTPP was obtained as purple micro crystal. Yield $335 \mathrm{mg}, 31.5 \%$; $\mathrm{mp}$. $>300^{\circ} \mathrm{C}$; IR (KBr) $1620 \mathrm{~cm}^{-1}, v_{\mathrm{C}=\mathrm{c}} ;{ }^{1} \mathrm{H}$ NMR $\left(\mathrm{CDCl}_{3}, 270 \mathrm{MHz}\right) \delta-2.75(\mathrm{~s}, 2 \mathrm{H}), \delta 5.47(\mathrm{~d}$, $1 \mathrm{H}, J=10 \mathrm{~Hz}), \delta 6.05(\mathrm{~d}, 1 \mathrm{H}, J=18 \mathrm{~Hz}), \delta 7.05$ $(\mathrm{q}, 1 \mathrm{H}, J=10 \mathrm{~Hz}), \delta 7.60-7.85(\mathrm{~m}, 11 \mathrm{H})$, $\delta 8.10-8.32(\mathrm{~m}, 8 \mathrm{H}), \delta 8.82(\mathrm{~s}, 8 \mathrm{H})$. Anal. Calcd for $\mathrm{C}_{46} \mathrm{H}_{32} \mathrm{~N}_{4}$ : C, 86.22\%; H, 5.03\%; N, $8.74 \%$. Found: C, $85.91 \%$; H, 4.84\%; N, $8.56 \%$. FD-Mass Calcd 640, Found 640.

\section{RADICAL POLYMERIZATION}

\section{Homopolymerization (Scheme 2)}

VTPP $\left(41.7 \mathrm{mg}, 6.51 \times 10^{-2} \mathrm{mmol}\right)$ and AIBN ( $1 \mathrm{~mol} \%$ of the monomer) were dissolved in benzonitrile $(0.10 \mathrm{ml})$. The solution was placed in a glass ampoule, degassed three times with an oil diffusion pump after three times with a rotary pump, sealed under high vacuum, and polymerized at $60^{\circ} \mathrm{C}$ for $60 \mathrm{~h}$. The solution was poured into acetone and the 
A. KaJiwara et al.

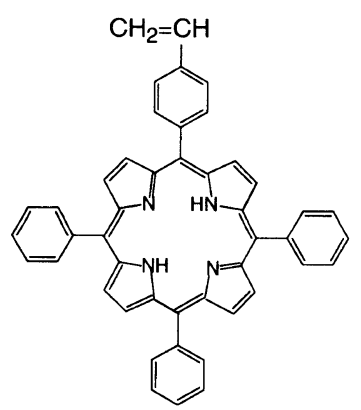

(3): VTPP

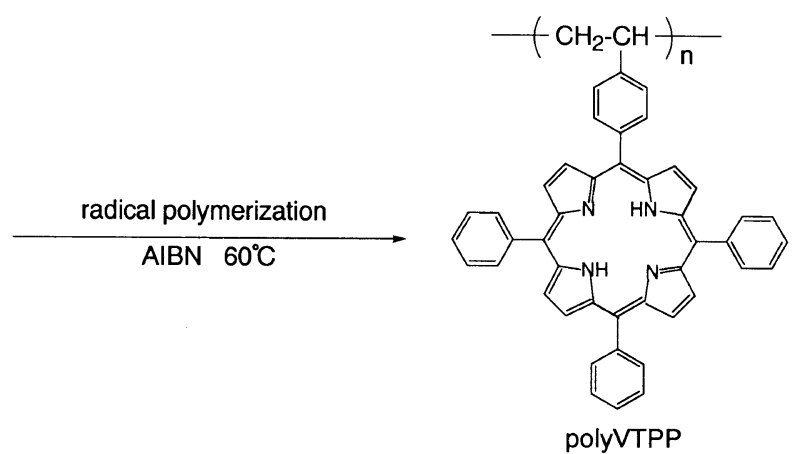

Scheme 2.

Table I. Radical polymerizations of VTPP and other TPP-containing monomers ${ }^{\mathbf{a}}$

\begin{tabular}{|c|c|c|c|c|c|c|c|}
\hline \multirow{2}{*}{ Monomer } & \multirow{2}{*}{$\frac{10^{2}[\text { monomer }]}{\mathrm{mol} \mathrm{cm}^{-3}}$} & \multirow{2}{*}{$\frac{10^{4}[\mathrm{AIBN}]}{\mathrm{mol} \mathrm{dm} \mathrm{m}^{-3}}$} & \multirow{2}{*}{ Solvent } & \multirow{2}{*}{$\frac{\text { Time }}{\mathrm{h}}$} & \multirow{2}{*}{$\frac{\text { Yield }^{\mathrm{b}}}{\%}$} & \multirow{2}{*}{$\bar{M}_{w}^{\mathrm{b}, \mathrm{c}}$} & \\
\hline & & & & & & & \\
\hline \multirow[t]{3}{*}{ VTPP } & 65.0 & 65.0 & $\mathrm{C}_{6} \mathrm{H}_{5} \mathrm{CN}$ & 60 & 71.9 & 107000 & This work \\
\hline & 30.0 & 30.0 & benzene & 60 & 66.5 & $91000^{d}$ & This work \\
\hline & 30.0 & 30.0 & THF & 60 & 64.3 & 178000 & This work \\
\hline \multirow[t]{2}{*}{ MAOTPP } & 11.1 & 2.18 & $\mathrm{C}_{6} \mathrm{H}_{5} \mathrm{CN}$ & 50 & 36.7 & 83000 & Ref 5 \\
\hline & 2.54 & 0.49 & DMF & 50 & 18.2 & 45000 & $\operatorname{Ref} 5$ \\
\hline \multirow[t]{3}{*}{ АОTPP } & 10.8 & 15.9 & $\mathrm{C}_{6} \mathrm{H}_{5} \mathrm{CN}$ & 50 & 49.7 & 10000 & $\operatorname{Ref} 5$ \\
\hline & 9.92 & 1.72 & DMF & 50 & 56.8 & 69000 & Ref 5 \\
\hline & 1.85 & 1.21 & $\mathrm{THF}$ & 50 & 28.3 & 8000 & $\operatorname{Ref} 5$ \\
\hline
\end{tabular}

a At $60^{\circ} \mathrm{C}$.

b Acetone-insoluble part.

c GPC, calibrated with standard polystyrene.

d $\bar{M}_{n}=34000, \bar{M}_{w} / \bar{M}_{n}=2.68$.

precipitated polymer was separated by centrifugation. This dissolution-precipitationseparation process was repeated three times to purify the polymer. The obtained polymer was dried with heating in vacuo. The polymer was purple solid. Anal. Calcd for $\left(\mathrm{C}_{46} \mathrm{H}_{32} \mathrm{~N}_{4}\right)_{n}$ : C, $86.22 \%$; H, 5.03\%; N, 8.74\%. Found: C, $85.06 \% ; \mathrm{H}, 5.19 \% ; \mathrm{N}, 8.74 \% . \bar{M}_{w}$ and $\bar{M}_{n}$ were determined by GPC calibrated by standard polystyrenes. Results of homopolymerization are summarized in Table I.

\section{Copolymerization}

Copolymerizations of VTPP with styrene were performed with AIBN at $60^{\circ} \mathrm{C}$ in benzonitrile. The total molar concentration of VTPP and styrene was $0.5 \mathrm{M}$, and AIBN was
$0.2 \mathrm{~mol} \%$ of the monomer concentration. Purification of the copolymers and estimation of the molecular weights were performed as described in homopolymerization. Copolymer compositions were estimated by elemental analysis. The monomer reactivity ratios were evaluated according to the Fineman-Ross method. ${ }^{14}$

\section{Physicochemical Measurements}

Visible spectra were measured in chloroform with Shimadzu UV-2100 spectrometer. Infrared spectra were recorded in $\mathrm{KBr}$ disks on JASCO FT/IR-3 spectrometer. Frequency calibration of the spectra was carried out with polystyrene. GPC analyses were performed by TOSOH CCP\&8010 series high-speed liquid 
chromatograph system by using TSK gel and THF as an eluent. TOSOH UV-8010 and TOSOH RI-8012 detectors were used. ${ }^{1} \mathrm{H}$ NMR spectra were obtained on JEOL JNM-GSX-400, JNM-GX 270 and Varian XL-100 spectrometers as $\mathrm{CDCl}_{3}$ solutions at $30^{\circ} \mathrm{C}$. Mass spectra were taken on a JEOL JMS SX-102 mass spectrometer by a field desorption (FD) method, an electron impact (EI) method, or a fast atom bombardment (FAB) method. Mass number was calibrated using cesium iodide (CsI). Time-resolved ESR experiments were performed on a JEOL JES-FE1X spectrometer operated without magnetic field modulation. Laser pulses were irradiated by using a Q-switched Nd: YAG laser (Quantaray DCR-2) operated at the third harmonic $(54 \mathrm{~mJ}$ per flash at $355-\mathrm{nm}$ with a $6-\mathrm{ns}$ fwhm). The technique of recording ESR spectra of transient diphenyl phosphonyl radicals in liquid solution has been described in detail in previous publication. ${ }^{15}$

\section{RESULTS AND DISCUSSION}

\section{Radical Polymerization}

The radical polymerizations of VTPP were homogeneous in benzonitrile, benzene and THF. The polymerized products were purified by repeated reprecipitation from THF-acetone. Polymers were obtained as deep purple powder. The results of the radical polymerization of VTPP are summarized in Table I along with other vinyl monomers having TPP moieties. Monomer concentration was restricted by the low solubility of these monomers. PolyVTPP was soluble in chloroform, dichloromethane, benzene, toluene, DMF, THF, and benzonitrile and insoluble in hexane, acetone, ethanol, methanol, diethyl ether, and water.

The IR spectrum of polyVTPP is shown in Figure 1 along with that of VTPP. The IR band of the monomer at $1620 \mathrm{~cm}^{-1}$ is assignable to the $\mathrm{C}=\mathrm{C}$ stretching vibration mode. This band disappeared in the polymer. Absorption bands

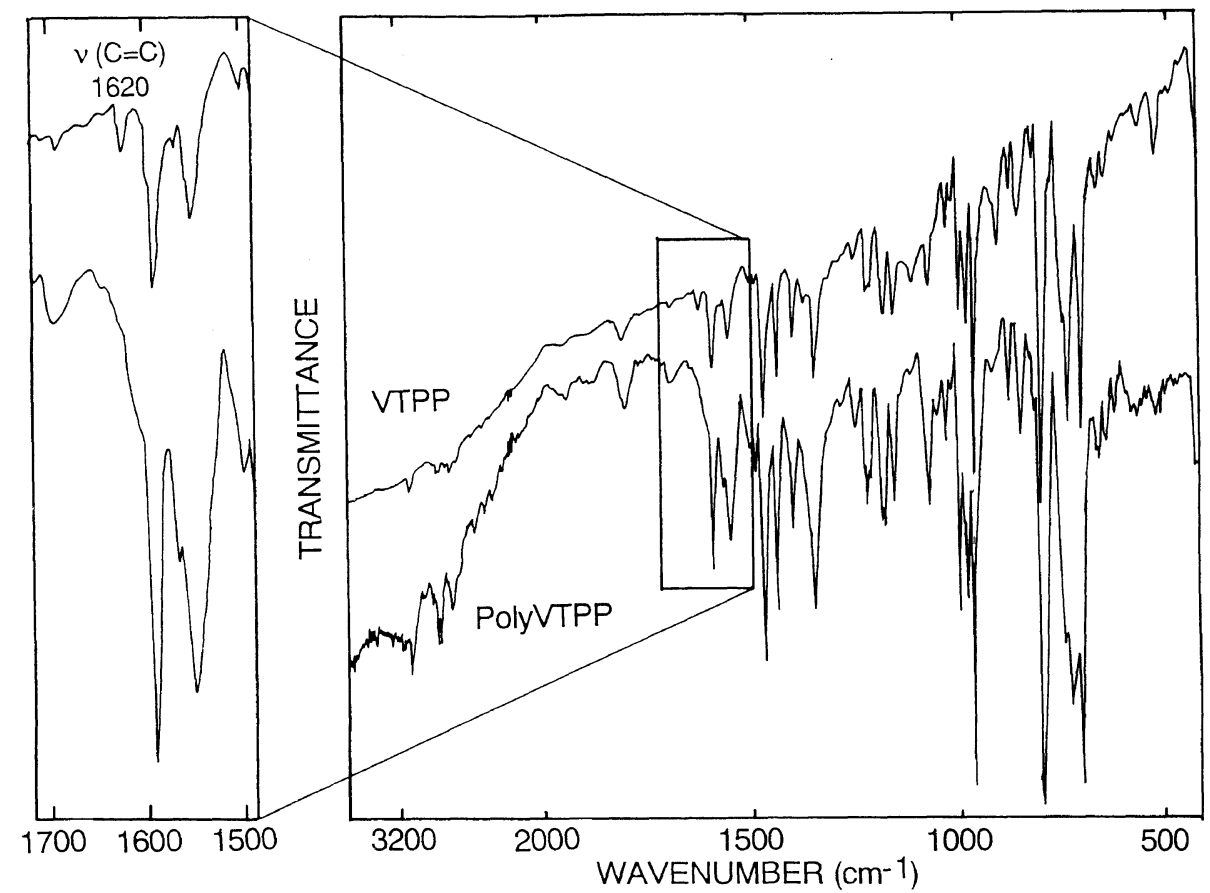

Figure 1. Infrared spectra of VTPP and poly VTPP (KBr). 


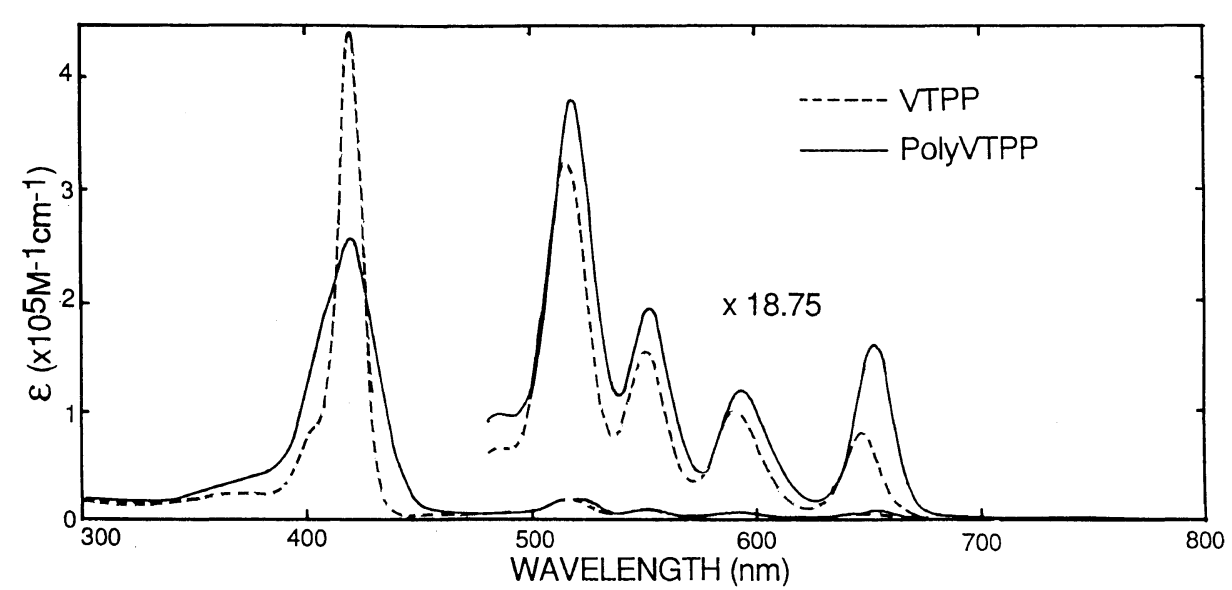

Figure 2. UV-visible absorption spectra of VTPP (--) and polyVTPP (-) in chloroform.

Table II. Radical copolymerizations of VTPP $\left(\mathrm{M}_{1}\right)$ and styrene $\left(\mathrm{M}_{2}\right)^{\mathrm{a}}$

\begin{tabular}{|c|c|c|c|c|c|c|c|}
\hline \multirow{2}{*}{ Run } & \multicolumn{2}{|c|}{ Monomer/mol\% } & \multirow{2}{*}{ Time/h } & \multirow{2}{*}{ Conc./h } & \multicolumn{2}{|c|}{ Copolymer/mol\% } & \multirow{2}{*}{$\bar{M}_{w} \times 10^{4}$} \\
\hline & [Styrene] & [VTPP] & & & [Styrene] & [VTPP] & \\
\hline 1 & 12 & 88 & 8.8 & 6.1 & 11 & 89 & 7.1 \\
\hline 2 & 14 & 86 & 8.3 & 4.6 & 24 & 76 & 8.8 \\
\hline 3 & 33 & 67 & 7.5 & 6.0 & 37 & 63 & 9.1 \\
\hline 4 & 34 & 66 & 8.0 & 6.7 & 34 & 66 & 7.4 \\
\hline 5 & 58 & 42 & 5.3 & 9.3 & 62 & 38 & 11 \\
\hline 6 & 67 & 33 & 12.8 & 4.0 & 56 & 44 & 40 \\
\hline 7 & 67 & 33 & 5.1 & 8.3 & 63 & 37 & 12 \\
\hline 8 & 75 & 25 & 3.0 & 2.9 & 68 & 32 & 4.8 \\
\hline 9 & 83 & 17 & 3.0 & 1.1 & 73 & 27 & 5.9 \\
\hline 10 & 88 & 12 & 2.5 & 1.3 & 83 & 17 & 4.2 \\
\hline
\end{tabular}

${ }^{\mathrm{a}}[$ Styrene $]+[\mathrm{VTPP}]=50 \mathrm{mM}$ in all runs.

characteristic of the porphyrin ring remained unchanged after polymerization. This indicates that the polymerization occurred though $\mathrm{C}=\mathrm{C}$ double bonds of the vinyl group.

Visible spectra of VTPP and polyVTPP are shown in Figure 2. VTPP has a Soret band at $419.0 \mathrm{~nm}$ and $\mathrm{Q}$ bands at 518.5, 552.5, 593.0, and $652.5 \mathrm{~nm}$. The spectrum of VTPP is similar to that of TPP, indicating that the presence of the vinyl group has no influence on the absorption of the porphyrin ring. PolyVTPP exhibits a Soret band at $419.5 \mathrm{~nm}$, with the $Q$ bands at 518.5, 552.5, 593.0, and $652.5 \mathrm{~nm}$. Close examination of these spectra shows that the Soret band of polyVTPP is weaker and broader than that of VTPP, indicating that the molecular extinction coefficient markedly decreases in the polymer. The molecular extinction coefficients of all $\mathrm{Q}$ bands of polyVTPP are almost comparable to those of the monomer. These results indicate that some electronic interactions occurred among porphyrin moieties in the polymer. This finding is almost the same as for other porphyrin containing polymers we have reported. Similar phenomena have been observed for porphyrin dimers in organic solvents and explained in terms of an exciton coupling model due to the close 
approach of the two porphyrin rings. ${ }^{16,17}$ The differences in the spectra between poly VTPP and VTPP suggest that the TPP moieties bound to this polymer are forced to interact due to their proximity.

\section{Copolymerization}

To understand the effects of the TPP ring on the radical reactivity of the vinyl monomers, copolymerizations of VTPP $\left(\mathbf{M}_{1}\right)$ with styrene $\left(\mathrm{M}_{2}\right)$ were performed in benzonitrile at $60^{\circ} \mathrm{C}$

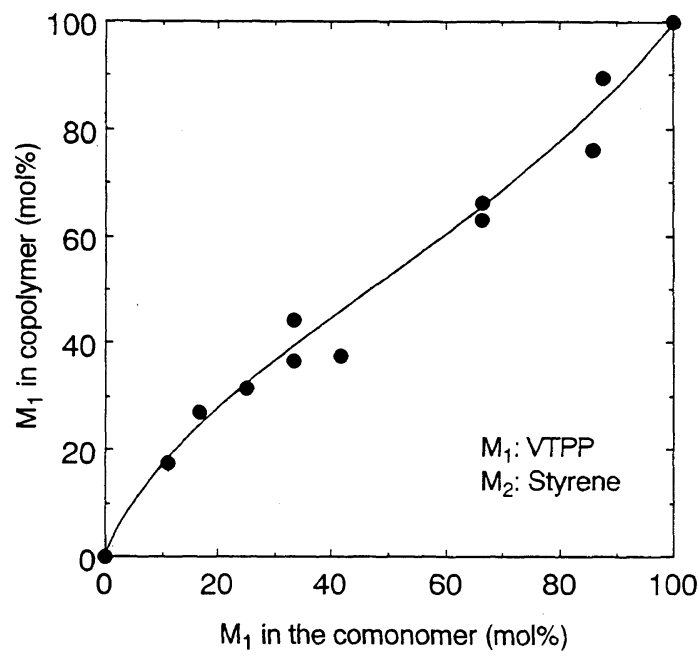

(a)

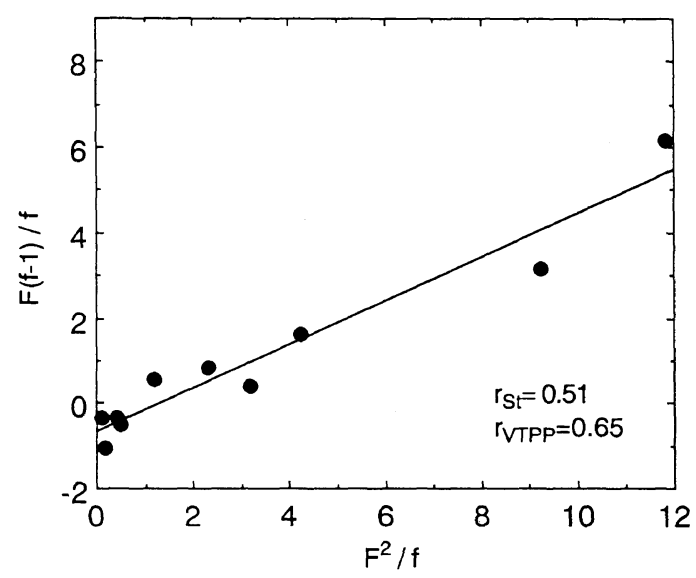

(b)

Figure 3. (a) Copolymer composition curve of VTPP $\left(M_{1}\right)$ with styrene $\left(M_{2}\right)$. (b) Fineman-Ross plots of copolymerization of VTPP with styrene. with AIBN as an initiator (Table II). The copolymer composition curve is shown in Figure 3 (a). Monomer reactivity ratios were determined to be $r_{1}=0.65 \pm 0.15$ and $r_{2}=$ $0.51 \pm 0.15$ by the Fineman-Ross method, ${ }^{12}$ indicating that the radical end of VTPP is more reactive toward styrene than VTPP, and that of styrene somewhat more reactive toward VTPP than styrene. We can see from these findings that copolymer tends to have relatively alternate composition. $Q$ and $e$ for VTPP were 0.85 and 0.24 , respectively. These values for VTPP are compared with those for styrene, MAOTPP, and MMA in Table III. When we compare $e$ of VTPP with that of styrene, VTPP shows more positive value than that of styrene by $\sim 1.0$. Similarly, MAOTPP has more positive $e$ value than that of MMA by $\sim 1.0 .^{5}$ This indicates that porphyrin moiety has more electron withdrawing substituents than phenyl or methyl group to the vinyl group. $Q$ of MAOTPP, 2.03, was previously found to be larger than that of MMA by $\sim 1.3$, which was explained by the resonance stabilization of vinyl group and TPP moiety through the ester bond. $Q$ of VTPP is smaller than that of styrene. The difference in $Q$ between styrene and VTPP has reverse tendency to that between MMA and MAOTPP. Since the vinyl group bind directly to TPP in VTPP, the resonance stabilization between vinyl group and TPP is considered to be hindered by steric repulsion between the vinyl group and bulky TPP, suggesting Q of VTPP to be smaller than that of styrene. Therefore, resonance stability of VTPP is similar to that of MMA rather than styrene. In fact, the copolymer composition curve of VTPP and styrene is similar to that

Table III. $Q$ and $e$ for monomers

\begin{tabular}{llrl}
\hline Monomer & $Q$ & \multicolumn{1}{c}{$e$} & \\
\hline VTPP & 0.85 & 0.24 & This work \\
Styrene & 1 & -0.80 & Ref 18 \\
MAOTPP & 2.03 & 1.47 & Ref 5 \\
MMA & 0.78 & 0.40 & Ref 18 \\
\hline
\end{tabular}




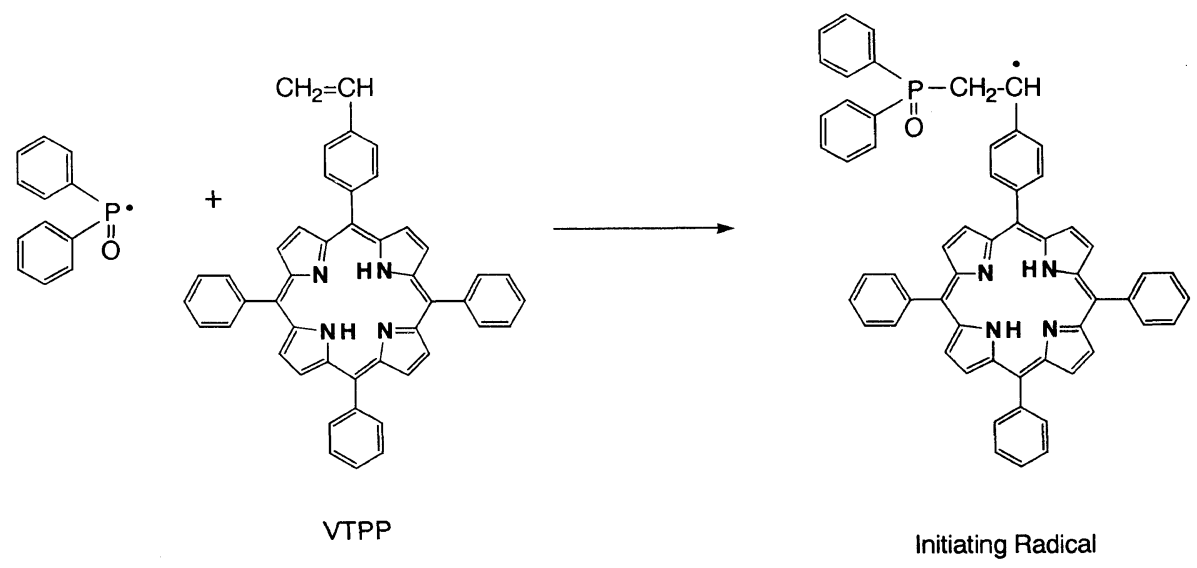

Scheme 3.

of MMA and styrene. ${ }^{19}$

\section{Time-Resolved ESR Study}

To evaluate the reactivity of VTPP to primary radicals in the radical polymerization, rate constant of the addition of diphenyl phosphinoyl radicals $\left(\mathrm{Ph}_{2} \dot{\mathrm{P}}=\mathrm{O}\right)$, generated by the photolysis of 2,4,6-trimethylbenzoyl diphenylphosphine oxide (TMDPO), to VTPP was directly determined by time-resolved electron spin resonance (ESR) spectroscopy. Recently, we reported a time-resolved ESR study on the initiation step of the photoinitiation of various monomers with TMDPO, whose photodissociation yielded the 2,4,6-trimethylbenzoyl radical and diphenyl phosphinoyl radical. ${ }^{13}$ We extended this research to the photoinitiation of VTPP with TMDPO (Scheme 3).

While decay rate of diphenyl phosphinoyl radical became higher with increasing the concentration of VTPP, the decay rate of 2,4,6-trimethylbenzoyl radical scarcely changed with increasing concentration of monomer. This shows that diphenylphosphinoyl radical is much more reactive with VTPP as well as other vinyl compounds than 2,4,6-trimethylbenzoyl radical. The decay rate of diphenylphosphinoyl radical increased with the concentrations of monomers, and followed first order kinetics even in the presence of monomers. The initiation rate constants for the addition of the

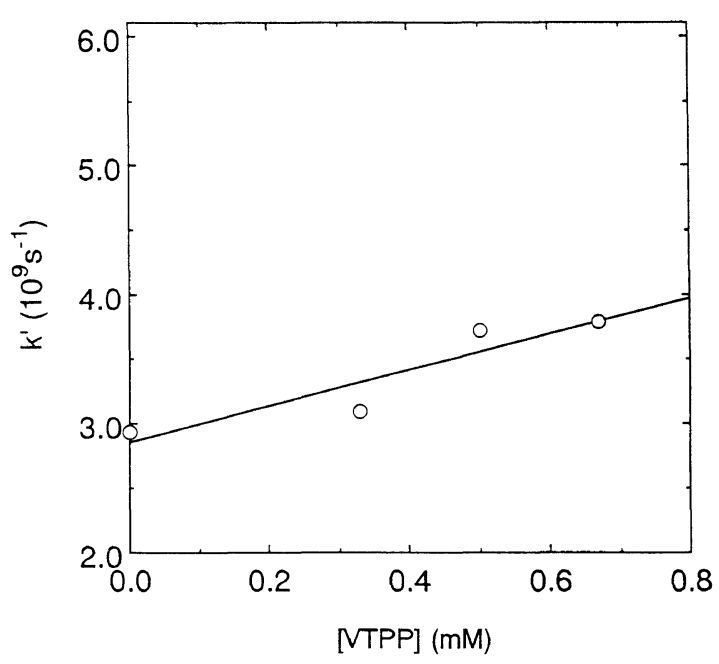

Figure 4. Plots of $k^{\prime}$ vs. the concentration of added monomer (VTPP).

diphenyl phosphinoyl radical to VTPP and styrene were estimated from the relation between the concentrations and decay rates (Figure 4). The rate constant for VTPP was $(1.4 \pm 0.5) \times 10^{6} \mathrm{~s}^{-1} \mathrm{M}^{-1}$. The initiation rate constant of VTPP was one order of magnitude smaller than that of styrene $\left((1.1 \pm 0.2) \times 10^{7}\right.$ $\left.\mathrm{s}^{-1} \mathrm{M}^{-1}\right)^{15}$ just like the case between MAOTPP and MMA. ${ }^{20} Q$ of VTPP was smaller than that of styrene as mentioned in the former section concerned with the results of copolymerization. $\mathrm{A} \quad \mathrm{C}=\mathrm{C}$ stretching vibration of IR spectrum of VTPP $\left(1620 \mathrm{~cm}^{-1}\right)$ 
is $16 \mathrm{~cm}^{-1}$ smaller than that of styrene $\left(1636 \mathrm{~cm}^{-1}\right)$, suggesting that the $\mathrm{C}=\mathrm{C}$ bond of VTPP is a little closer to the single bond than that of styrene. Accordingly, the difference in the rate constants between VTPP and styrene is due to decreased resonance stabilization of vinyl group of VTPP, in other words, the steric bulkiness of TPP moiety of VTPP decreases the resonance stabilization of the vinyl group.

Acknowledgment. This research was partly supported by a Grant-in-Aid for Scientific Research on Priority Area 'Molecular Magnetism' (Area No. 228/04 242 104) from the Ministry of Education, Science, and Culture of Japan.

\section{REFERENCES}

1. a) A. A. Ovchinnikov, Dokl. Acad. Nauk. USSR, 236, 928 (1978). b) A. L. Buchachenko, Dokl. Acad. Nauk. USSR, 244, 1146 (1979).

2. M. Kamachi, H. Akimoto, W. Mori, and M. Kishita, Polym. J., 16, 23 (1984).

3. S. Nozakura and M. Kamachi, Makromol. Chem. Suppl., 12, 255 (1985).

4. M. Kamachi, H. Akimoto, and S. Nozakura, $J$. Polym. Sci., Polym. Lett. Ed., 21, 693 (1983).

5. M. Kamachi, X. S. Cheng, T. Kida, A. Kajiwara, M. Shibasaka, and S. Nagata, Macromolecules, 20, 2665 (1987).

6. A. Kajiwara, K. Aramata, S. Nomura, Y. Morishima, and M. Kamachi, Chem. Lett., 95, (1992).

7. M. Kamachi, A. Kajiwara, and K. Aramata, to be published.

8. M. Kamachi, M. Shibasaka, A. Kajiwara, W. Mori, and M. Kishita, Bull. Chem. Soc., Jpn., 62, 2465 (1989).

9. M. Kamachi, X. S. Cheng, H. Aota, W. Mori, and M. Kishita, Chem. Lett., 2231 (1987).

10. M. Kamachi, X. S. Cheng, and S. Nozakura, Preprints, "Fifth Rare Earth Symposium," Organized by the Rare Earth Society of Japan, Tokyo, 1987, $2 \mathrm{~B} 05$.

11. M. Kamachi, A. Kajiwara, and K. Aramata, to be published.

12. D. D. Perrin and W. L. F. Armarego, "Purification of Laboratory Chemicals," 3rd ed, Pergamon Press, Oxford, England, 1988.

13. T. Chihara, T. Wakabayashi, and K. Taya, Chem. Lett., 1657 (1981).

14. R. Fineman and S. D. Ross, J. Polym. Sci., 5, 269 (1950).

15. A. Kajiwara, Y. Konishi, Y. Morishima, W. Schnabel, K. Kuwata, and M. Kamachi, Macromolecules, 26, 1656 (1993).

16. I. W. White, in "Porphyrins," Vol. 4, M. Dolphin, Ed., Academic Press, New York, N.Y., 1973, pp 306-325.

17. M. Goutermann, D. Holten, and D. Libermann, Chem. Phys., 25, 139 (1977).

18. J. Brandrup and E. H. Immergut, Ed., "Polymer Handbook," 3rd ed, John-Wiley \& Sons, New York, N.Y., 1989, pp II/268-269.

19. T. Ito and T. Otsu, J. Macromol. Sci.-Chem., A3, 197 (1969).

20. M. Kamachi, Y. Morishima, A. Kajiwara, and K. Aramata, to be published. 